\title{
Development of a real-time PCR assay for direct detection and quantification of Bacillus sporothermodurans in ultra-high temperature milk
}

\author{
M. Abouelnaga, ${ }^{*} \dagger$ A. Lamas, ${ }^{*}$ J. M. Miranda, ${ }^{*}$ M. Osman, $\dagger$ A. Cepeda, ${ }^{*}$ and C. M. Franco*1 \\ *Department of Analytical Chemistry, Nutrition and Food Science, Faculty of Veterinary, University of Santiago de Compostela, Lugo 27002, Spain \\ †Dairy Department, Faculty of Agriculture, Suez Canal University, Ismailia 41522, Egypt
}

\begin{abstract}
In our study, a new and highly sensitive real-time PCR Taqman assay was developed for the direct and specific detection of Bacillus sporothermodurans in UHT milk. The target region was selected based on the $16 \mathrm{~S}$ rRNA gene profiles of 11 B. sporothermodurans from GenBank. A standard curve was created using a reference strain of B. sporothermodurans, DSM 10599. A low limit of detection for B. sporothermodurans in UHT milk (10 cfu/mL) was obtained. Furthermore, a total of 110 UHT milk samples from several supermarkets were directly assessed to detect and quantify $B$. sporothermodurans using the real-time PCR Taqman developed. The B. sporothermodurans counts obtained were highly correlated with the microbial plate counts in the UHT milk samples. This is the first time that B. sporothermodurans has been quantified directly from UHT milk. This technique could be applicable as a routine tool for preventing the growth of these bacteria by allowing for the rapid screening of raw milk samples in dairy plants. As expected, the probability of bacterial growth in UHT milk packages increased with the $B$. sporothermodurans counts in the raw milk.
\end{abstract}

Key words: Bacillus sporothermodurans, real-time PCR Taqman, ultra-high temperature milk

\section{INTRODUCTION}

Bacillus sporothermodurans is an important nonpathogenic bacterium in the dairy industry that can produce highly heat-resistant endospores that can survive UHT milk processing $\left(140^{\circ} \mathrm{C}\right.$ for a few seconds). These spores may germinate during storage in UHT products and grow up to $10^{5} \mathrm{cfu} / \mathrm{mL}$, causing instability due to their proteolytic activity (Klijn et al., 1997; Montanari et al., 2004). This is a common problem encountered in many dairy factories, reducing milk quality, shelf life,

Received January 4, 2016.

Accepted June 28, 2016

${ }^{1}$ Corresponding author: carlos.franco@usc.es and consumer acceptability (Pettersson et al., 1996). However, attempts to increase temperature or holding time could affect the organoleptic and nutritional qualities of the UHT milk (Claeys et al., 2001).

Bacillus sporothermodurans was first detected in UHT milk in Italy and Austria in 1985 and then also in Germany in 1990 (Hammer et al., 1995). This microorganism has also been found in sterilized milk and other products such as chocolate milk, evaporated milk, and reconstituted milk (Herman et al. 2000). Directive 92/46 of the European Union related to milk and dairy products establishes that the general bacterial plate counts of heat-treated milk products after $15 \mathrm{~d}$ of incubation at $30^{\circ} \mathrm{C}$ must be below $10 \mathrm{cfu}$ per $0.1 \mathrm{~mL}$ (European Council, 1992). Therefore, the spores of $B$. sporothermodurans that survive after the sterilization process become an obstacle for dairy factories in meeting the legal requirements established by European legislation.

The detection of B. sporothermodurans is usually performed using culture techniques that include the use of brain heart infusion (BHI) agar after heating the sample $100^{\circ} \mathrm{C}$ for 30 to $40 \mathrm{~min}$ (Scheldeman et al., 2006). In addition, different molecular methods have been used to identify and characterize $B$. sporothermodurans. For instance, this bacterium has been identified by conventional PCR methods using specific primers based on the 16S rRNA gene (Scheldeman et al., 2002), which has regions with high variability for identifying B. sporothermodurans (Klijn et al., 1997). Likewise, a conventional PCR assay was modified to include propidium monoazide to detect viable $B$. sporothermodurans (Cattani et al., 2013). Although these studies have been conducted over the last decade, no attention has been paid to quantitative detection. Real-time PCR (RTiPCR), which is widely used in food microbiology, is an accurate and rapid quantitative detection technique. For instance, Staphylococcus spp., Coxiella burnetii, and Streptococcus agalactiae (Zanardi et al., 2014; Van den Brom et al., 2015; Zhang et al., 2015) have all been verified using RTi-PCR. In one study, Tabit and Buys (2011) used RTi-PCR SYBR Green to detect B. sporo- 
thermodurans in a pure culture. However, this method has not been applied directly to milk samples, and no quantification was applied for this bacterium. Moreover, RTi-PCR Taqman assays have not been proven effective for the detection and quantification of B. sporothermodurans in either pure cultures or milk samples directly. Hence, the aim of this study is to develop a direct and accurate RTi-PCR Taqman assay for the direct rapid quantitative screening of $B$. sporothermodurans in UHT milk. So this method could not only be used to control large amounts of UHT milk batches but also to control a large amount of raw milk samples or environmental samples previously submitted to heat treatment to avoid this problem in the milk industry.

\section{MATERIALS AND METHODS}

\section{Primer-Probe Design and Real-Time Conditions}

A new design for a probe and primers was applied for the detection and quantification of B. sporothermodurans using the RTi-PCR reaction (forward, 5'-ACCAGGTCTTGACATCCTCTTGA-3'; reverse, $\quad$ 5'-ATGCACCACCTGTCACTCTTGT-3'; and probe, 5'-CTAGAGATAGGGATTTCC-3'). The target sequence was selected based on the $16 \mathrm{~S}$ rRNA gene profiles of 11 B. sporothermodurans from the National Center for Biotechnology Information (NCBI) database. These sequences were aligned together using CLUSTAL X software (Larkin et al., 2007; accession numbers KC618495.1, NR_118833.1, NR_118832.1, NR_026010.1, JX569192.1, GU238287.1, AJ302942.1, AJ302941.1, AB190039.1, FJ188308.1, and HQ713507.1). A conserved alignment region targeting $B$. sporothermodurans was applied in the design of the primers and the Taqman probe using Primer Express software v2.0 (Applied Biosystems, Foster City, CA). Based on the alignments of the B. sporothermodurans sequences with reference sequences, primers and an MGB Taqman probe were designed using fragments of $76 \mathrm{bp}$ as part of a $16 \mathrm{~S}$ rRNA gene. Amplification by real-time PCR was performed using ABI PRISM 7000 (Applied Biosystems) under the following conditions: $10 \mathrm{~min}$ at $95^{\circ} \mathrm{C}$, followed by 45 cycles of $15 \mathrm{~s}$ at $95^{\circ} \mathrm{C}$ for denaturation, and $1 \mathrm{~min}$ at $60^{\circ} \mathrm{C}$ for annealing and extension. Then, a $25-\mu \mathrm{L}$ reaction volume was amplified, including $7.5 \mu \mathrm{L}$ of template DNA, $12.5 \mu \mathrm{L}$ of Environmental Master Mix, $900 \mathrm{n} M$ of each primer, and $200 \mathrm{n} M$ of the Taqman probe. All materials for the reaction were obtained from Applied Biosystems.

The specificity of the probe and primers were tested experimentally using positive reference strains and a negative control panel from different bacteria (Table 1).

\section{Standard Curve}

The developed primers and Taqman probe were employed using triplicate amplifications of the reference

Table 1. Real-time PCR Taqman assay specificity for detection of Bacillus sporothermodurans ${ }^{1}$

\begin{tabular}{llc}
\hline Strain & Origin & Results $^{2}$ \\
\hline Bacillus sporothermodurans DSM No. 10599 & DSM & $(+)$ \\
B. sporothermodurans LMG 17668 & LMG & $(+)$ \\
Bacillus acidicola DSM 14745 & DSM & $(-)$ \\
Bacillus coagulans DSM 1 & DSM & $(-)$ \\
Bacillus subtilis ATCC 11774 & ATCC & $(-)$ \\
B. subtilis ATCC 9524 & ATCC & $(-)$ \\
Bacillus cereus ATCC 14893 & ATCC & $(-)$ \\
Bacillus licheniformis ATCC 14580 & ATCC & $(-)$ \\
Bacillus megaterium ATCC 25848 & ATCC & $(-)$ \\
Bacillus thuringiensis ATCC 33679 & ATCC & $(-)$ \\
Pseudomonas fragi ATCC 4973 & ATCC & $(-)$ \\
Enterococcus faecalis LMG20863 & LMG & $(-)$ \\
E. faecalis CECT 481 & CECT & $(-)$ \\
Enterococcus thailandicus & Lhica Lab & $(-)$ \\
Enterococcus casseliflavus & Lhica Lab & $(-)$ \\
Staphylococcus caprae & Lhica Lab & $(-)$ \\
Streptococcus uberis & Lhica Lab & $(-)$ \\
Lactobacillus casei & Lhica Lab & $(-)$ \\
\hline
\end{tabular}

${ }^{1}$ DSM were obtained from Deutsche Sammlung von Mikroorganismen und Zellkulturen GmbH. LMG: Belgian Coordinated Collections of Microorganisms. ATCC: American Type Culture Collection. CECT: Collection Española de Cultivos Tipo. Lhica Lab: from our laboratory, the Hygiene Food Inspection and Control laboratory.

${ }^{2}(-)$ and $(+)$ are indicators for B. sporothermodurans detection according to standard curve. 
strain of B. sporothermodurans (DSM No. 10599) for a standard curve. Serial dilutions of reference strain cultures $\left(10^{8} \mathrm{cfu} / \mathrm{mL}\right)$ were prepared after inoculating UHT milk with the reference strains, with concentrations ranging from $10^{-1}$ to $10^{-7} \mathrm{cfu} / \mathrm{mL}$ as determined by plate counts, in BHI agar. The UHT milk used to construct the standard curve was previously tested for the presence of B. sporothermodurans, using the methodology described here, with no positive result.

Then, $700 \mu \mathrm{L}$ of UHT milk was inoculated with the reference strain, and DNA was directly extracted using the Prep SEQ extraction kit. Subsequently, $10^{-1}$ to $10^{-7}$ dilutions were surface plated on to BHI agar plates (Merck, Darmstadt, Germany). These plates were then incubated at $37^{\circ} \mathrm{C}$ for $48 \mathrm{~h}$.

\section{UHT Milk Samples, Reference Strains, and Microbial Plate Counts}

One hundred ten UHT milk samples were collected from 17 UHT manufacturers (A-Q) that had been bought from supermarkets. Of these, 98 samples were from cow milk, whereas 12 samples were from goat and sheep milk. The UHT milk samples were distributed in 2 groups: 61 samples of full-fat and 49 samples of skim milk. In addition, 2 reference strains of B. sporothermodurans (DSM No. 10599 and LMG 17668) were obtained from the Deutsche Sammlung von Mikroorganismen und Zellkulturen $\mathrm{GmbH}$ and the Belgian Coordinated Collections of Microorganisms, respectively. To make the initial dilution, $1 \mathrm{~mL}$ from the UHT milk samples was aseptically mixed with $9 \mathrm{~mL}$ of $0.1 \%$ peptone water (Merck). Appropriate dilutions were prepared $\left(10^{-1}\right.$ to $10^{-6}$ ) and subsequently surface-plated on BHI agar plates, followed by incubation at $37^{\circ} \mathrm{C}$ for $48 \mathrm{~h}$ (Merck). After the incubation period, 2 colonies were randomly selected from $22 \%$ ( 5 out of 23 ) of the positive UHT milk samples using conventional microbiological counts. All of these colonies (10 colonies) were subjected to functional and conventional microbiological tests (colony and bacterial morphology, Gram staining, catalase, and oxidase) and identified by molecular methods as is described in the following paragraph.

\section{Molecular Identification of Milk Isolates}

The DNA templates were extracted from 3-d-old pure cultures from BHI agar plates that had been identified by amplification and sequencing of the $16 \mathrm{~S}$ rRNA gene. Amplification of 800-bp fragment from the $16 \mathrm{~S}$ rRNA gene was performed with p8FPL (5'-AGTTTGATCCTGGCTCAG-3') and p806R (5'-GGACTAC-
CAGGGTATCTAAT-3') universal primers (McCabe et al., 1999), in a MyCycler Thermal Cycler (Bio-Rad Laboratories, Hercules, CA) under the following conditions: (1) initial denaturing step at $94^{\circ} \mathrm{C} / 7 \mathrm{~min}$; (2) 35 cycles of denaturation $\left(94^{\circ} \mathrm{C} / 60 \mathrm{~s}\right)$, annealing $\left(55^{\circ} \mathrm{C} / 60\right.$ $\mathrm{s})$, and extension $\left(72^{\circ} \mathrm{C} / 60 \mathrm{~s}\right)$; and (3) final extension at $72^{\circ} \mathrm{C} / 15$ min (McCabe et al., 1999). The same primers used for PCR were also employed to sequence both strands of the PCR products. Sequencing reactions were analyzed using an automatic sequencing system (ABI 3730XL DNA Analyzer, Applied Biosystems) with the POP-7 system and reviewed carefully using Chromas software (Griffith University, Queensland, Australia). All 16S rRNA sequences obtained were compared with the GenBank database of the NCBI as reference data (accession numbers of these sequences: NR_118833.1, NR_118832.1, and NR_026010.1).

\section{DNA Extraction for RTi-PCR}

Bacillus sporothermodurans was inoculated in BHI and incubated at $37^{\circ} \mathrm{C}$ for $48 \mathrm{~h}$. Afterward, $700 \mu \mathrm{L}$ of broth was taken in a clean tube and centrifuged at $13,000 \times g$ for $4 \mathrm{~min}$. The DNA templates were subsequently extracted from the pellets using a Rapid Spin Samples Preparation Kit, Prep SEQ (Applied Biosystems), as per the manufacturer's instructions, to extract the DNA from the bacteria and UHT milk samples. The DNA was then stored at $-20^{\circ} \mathrm{C}$.

\section{Quantitative Detection of B. sporothermodurans in UHT Milk Samples}

Direct screening for B. sporothermodurans in retail UHT milk samples was performed by RTi-PCR Taqman amplification using a new probe and primers. The DNA was extracted from $700 \mu \mathrm{L}$ of each UHT milk sample, following the previously described procedures. The same UHT milk samples quantified by RTi-PCR were subsequently surface-plated on BHI agar, followed by incubation at $37^{\circ} \mathrm{C}$ for $48 \mathrm{~h}$.

All determinations and quantifications of calibration curves were performed in triplicate, whereas the quantification of pure cultures and UHT milk samples was performed in duplicate. Cycle threshold $\left(\mathbf{C}_{\mathbf{T}}\right)$ values were plotted against counts (in $\log \mathrm{cfu} / \mathrm{mL}$ ) of the reference bacteria used. The efficiencies $(\mathbf{E})$ of the reactions were calculated from linear regression curves based on the formula described by Klein (2002). The E was calculated by the equation:

$$
\mathrm{E}=\left[10^{(-1 / \mathrm{SLOPE})}\right]-1 .
$$




\section{Statistical Analysis}

The data were compared using the nonparametric Mann-Whitney U-test. All statistical analyses were carried out using the IBM SPSS Statistics Package (version 19, 2010, IBM Corporation, Somers, NY).

\section{RESULTS}

\section{Primers and Probe Design and Specificity}

A new design for a Taqman probe and primers was generated for direct detection and quantification of $B$. sporothermodurans in UHT milk samples. A total of 110 samples of commercially available UHT milk were purchased from 17 different manufacturers and tested for $B$. sporothermodurans. Our results showed a high specificity in the RTi-PCR Taqman for B. sporothermodurans using positive reference strains and a negative control panel from other species (Table 1).

According to the generated standard curve (Figure 1 ), $\mathrm{C}_{\mathrm{T}}$ values $>38.03$ were considered as no amplification in the extracted DNA. In addition, the limit of detection for this assay was $1 \log \mathrm{cfu} / \mathrm{mL}$ of UHT milk. The standard curve also showed a good correlation coefficient in the linear regression analysis (0.98) for extracted DNA. The curve slope for B. sporothermodurans was -3.1536 , while the $\mathrm{E}$ of the reactions was $107 \%$, which was calculated from the linear regression curve.

\section{Quantitative Detection of B. sporothermodurans in UHT Milk Samples}

Bacillus sporothermodurans was detected and quantified in the UHT milk samples according to the standard curve. The accuracy of the Taqman probe assay was confirmed by comparing the values from the bacterial

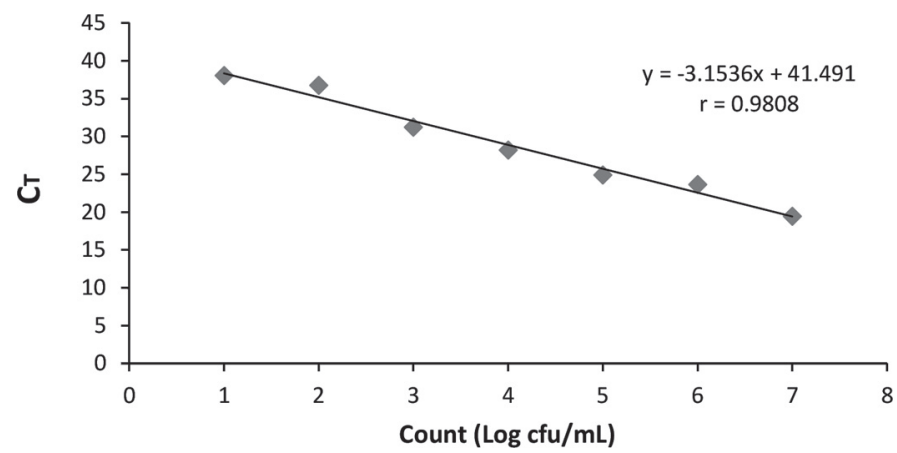

Figure 1. Standard curve of real-time PCR (RTi-PCR) of 10-fold serial dilution of Bacillus sporothermodurans. Cycle threshold $\left(\mathrm{C}_{\mathrm{T}}\right)$ values are plotted against colony-forming unit count. counts with the plotted values $\left(\mathrm{C}_{\mathrm{T}}\right)$, using the standard curves from the extracted DNA from BHI broth.

Thirty-two out of 110 of the retail UHT milk samples were contaminated with $B$. sporothermodurans. Although 17 manufacturers were used, only UHT milk samples from 5 were positive for $B$. sporothermodurans. Furthermore, 9 out of the 32 positive UHT milk samples, from 2 manufacturers $(\mathrm{B})$ and $(\mathrm{K})$, were not detected by conventional plate counts on BHI agar. However, these patterns of quantification, using RTiPCR Taqman and bacterial plate counts, did not reveal a significant difference $(P>0.05)$. Bacillus sporothermodurans isolates were confirmed by amplification and subsequent sequencing of the $16 \mathrm{~S}$ rRNA gene. All the colonies showed rod-shaped cells, positive to the Gram reaction, catalase, and oxidase tests. As shown in Table 2, Bacillus sporothermodurans was also found in UHT goat milk samples. Despite the apparent difference between the number of $B$. sporothermodurans detected in UHT milk full-fat samples in comparison with skim milk samples, these differences were not statistically significant $(P>0.05)$ using the RTi-PCR method or the standard plate count method.

\section{DISCUSSION}

Bacillus sporothermodurans has been incriminated in massive contaminations of UHT milk products since the mid-1980s. However, it is difficult to isolate this microorganism from raw milk using conventional microbiological methods due to the existence of highly competitive microbiota (Scheldeman et al., 2006). Consequently, some studies have developed conventional PCR techniques to detect B. sporothermodurans (Herman et al., 1998; Scheldeman et al., 2002). Realtime PCR molecular techniques have not been used to quantify $B$. sporothermodurans directly from UHT milk samples. For instance, Tabit and Buys (2011) used a SybrGreen RTi-PCR technique to detect B. sporothermodurans, but only in pure cultures. Furthermore, RTi-PCR Taqman chemistry has not been reported yet in the scientific literature for the study of B. sporothermodurans for either pure culture or UHT milk samples. In addition, this method has been reported in the scientific literature to achieve higher sensitivity and specificity than the SybrGreen method (Lurchachaiwong et al., 2008).

The RTi-PCR Taqman has been successfully applied for the quantitative detection of specific genes in different foods (Ladero et al., 2010; Guarddon et al., 2011) or microorganisms, such as Salmonella in milk, yogurt, and cheese; Listeria monocytogenes in raw milk (ElSharoud, 2015; Paul et al., 2015); and Bacillus cereus, Bacillus licheniformis, and Bacillus subtilis in other 
ABOUELNAGA ET AL.

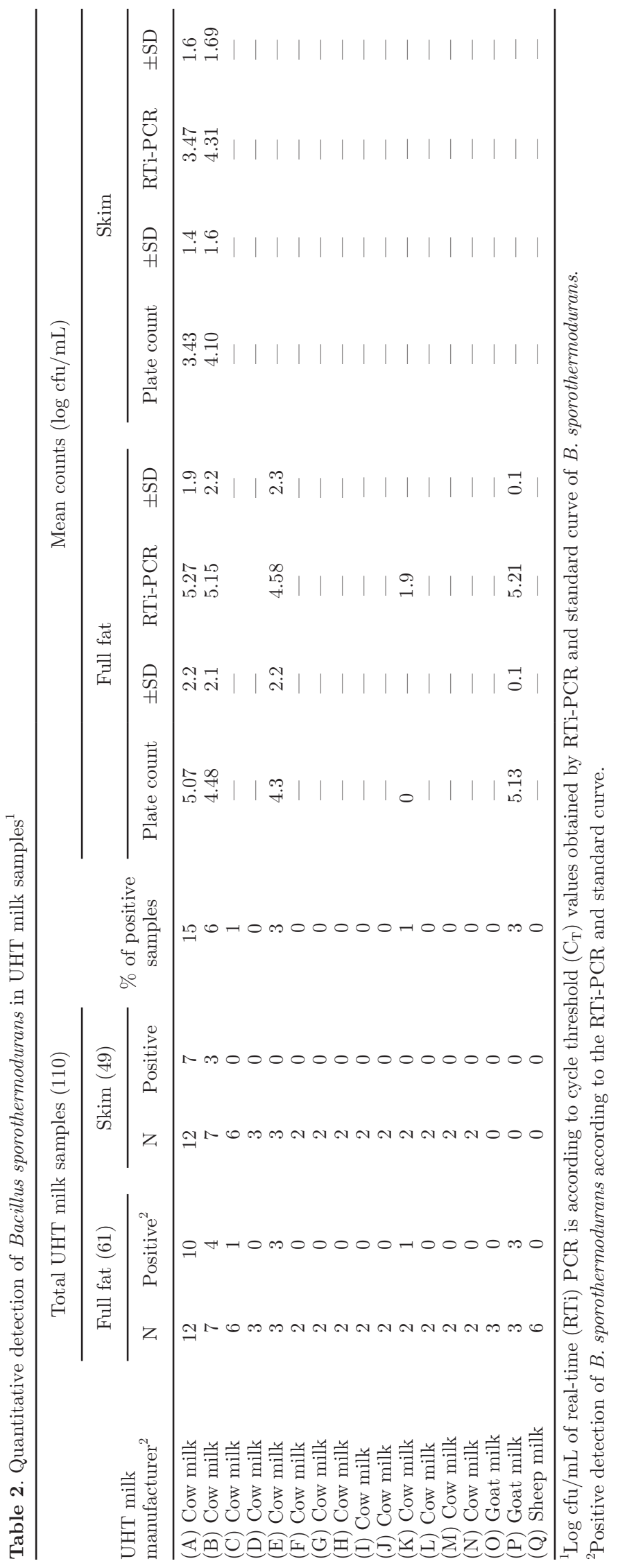


food products (Fernández-No et al., 2011). It is in this context that a reliable and sensitive RTi-PCR Taqman assay for the direct and specific detection of B. sporothermodurans in UHT milk products was developed in the present study.

A new design for a Taqman probe and primers was generated for the direct detection and quantification of B. sporothermodurans in UHT milk. Our method showed a good fit curve $(\mathrm{r} \geq 0.98)$ and a slope value $(-3.1536)$ close to the theoretical optimal value (-3.32; Higuchi et al., 1993), indicating that the assay appropriately quantified $B$. sporothermodurans. The efficiency of our assay was $107 \%$. In RTi-PCR assays, the accepted range of efficiency is 95 to $110 \%$ (West et al., 2007). This is because efficiency could be slightly decreased or increased by compounds presented in the sample matrix (Martínez-Blanch et al., 2009; Svec et al., 2015). The detection limit of the RTi-PCR Taqman assay was 10 bacteria per $\mathrm{mL}(1 \log \mathrm{cfu} / \mathrm{mL})$ of $B$. sporothermodurans in UHT milk samples, which confirms the sensitivity of this method for detecting and quantifying the target. Other authors have shown detection limits in food of above $1 \log \mathrm{cfu} / \mathrm{mL}$, as in the case of $B$. cereus, with a limit in food of $60 \mathrm{cfu} / \mathrm{mL}$ as reported by Martínez-Blanch et al. (2009) using a RTi-PCR Taqman assay. It is interesting to note that the detection limit for our new method complies with EU legislation for milk and dairy products (European Council, 1992), as well as other legal limits required in other countries.

In this study, RTi-PCR Taqman assays were used for first time to detect and quantify $B$. sporothermodurans in UHT milk samples via corresponding $\mathrm{C}_{\mathrm{T}}$ values (Table 2). The $\mathrm{C}_{\mathrm{T}}$ values were slightly lower than corresponding values of bacterial plate counts. However, a good correlation between bacterial plate counts from UHT milk samples and the RTi-PCR Taqman assay has been shown. These higher values obtained by the PCR method could be a result of the detection of DNA from dead bacterial cells. Additionally, and probably due to the same cause, some UHT milk samples from certain manufacturers also gave positive results in the RTi-PCR Taqman analysis but not on the plate counts (Table 2). Similar results related to higher counts using real-time methodology were also obtained by other authors with respect to conventional plate counts (Reichert-Schwillinsky et al., 2009) depending on the stress rate of the bacterial cells. Other authors tried to explain negative plate counts in detecting these spore-forming species as the result of inhibitory compounds, which are used in some factories, such as nisin and potassium sorbate, on spores and vegetative cells of $B$. sporothermodurans or in ultra-high-pressure homogenization treatments (Amador Espejo et al., 2014; Aouadhi et al., 2015).
However, in contrast to conventional PCR techniques (Scheldeman et al., 2002) and SybrGreen RTi-PCR chemistry (Tabit and Buys, 2011), RTi-PCR Taqman, which shows higher sensitivity and specificity, might be sufficiently effective for the specific quantification of $B$. sporothermodurans in UHT milk regarding safety and quality assessment.

Milk quality, good hygiene, and farm management practices are frequently monitored according to total bacterial count. Among the other microbiology-based tests that are carried out to assess the quality and safety of milk and dairy products are those designed to quantify thermoduric bacteria and specific pathogens (Gopal et al., 2015). However, B. sporothermodurans has never before been quantitatively detected directly in raw or UHT milk. Positive results in UHT milk samples taken from supermarkets confirmed that contamination with this species before the thermal treatment can negatively affect credibility and competitiveness in the dairy industry. According to the results obtained, this method could be used in dairy factories to control microorganisms in packaged UHT milk through the rapid screening of raw milk for high numbers of these thermoresistant bacteria before use in UHT milk production.

Bacillus sporothermodurans was only detected in samples from 5 manufacturers, with high numbers of B. sporothermodurans detected in 4 of these positive brands (Table 2), indicating the need to control these microorganisms at the source. High incidences of $B$. sporothermodurans were also reported by Tabit and Buys (2011). It is possible to explain the high mean count as part of the UHT process, with heat-resistant spores occurring more frequently in indirect UHT as compared with direct UHT processing (Scheldeman et al., 2006), in addition to milk contamination on the farm (Vaerewijck et al., 2001). These spore-forming bacteria have a negative effect on the quality, shelf life, and consumer acceptability of UHT milk (Pettersson et al., 1996; Herman et al., 1998). However, it is possible to control these problems by using our RTi-PCR Taqman assay to screen the spores or vegetative cells of B. sporothermodurans in a large number of raw milk samples in a rapid way (less than $2 \mathrm{~h}$ ) to identify dairy farms with high amounts of these bacteria. In any case, it should be pointed out that this method was carried out in UHT milk samples to prove the validity of RTi-PCR Taqman assay counts as compared with standard plate counts in milk samples naturally contaminated with these bacteria. The possible validation of the method by using natural raw milk would be very complex due to the presence of numerous other contaminant bacteria, and the absence of selective culture media to detect B. sporothermodurans. 
The results showed that the mean count of $B$. sporothermodurans was higher in UHT full-fat milk compared with samples of skim UHT milk (Table 2). Although no significant difference was found, the highest count in full-fat milk could be due to the ability of fat to relieve the effect of high temperatures on $B$. sporothermodurans (Ahmed et al., 1995). Likewise, no significant difference was found in the quantification of B. sporothermodurans using RTi-PCR Taqman and bacterial plate counts. This has confirmed the success of the RTi-PCR Taqman method for routine monitoring of B. sporothermodurans in dairy factories.

\section{CONCLUSIONS}

A new molecular assay was developed as a rapid, accurate, and direct method of quantitatively detecting B. sporothermodurans in UHT milk samples. Moreover, this method could help in tracing the abundance of $B$. sporothermodurans in raw milk samples or even in samples taken from the plant environment. The usefulness of this method was demonstrated using real UHT milk samples taken from supermarkets, proving that there are samples of UHT milk containing these bacteria in which conventional microbiological methods could not directly detect the presence of $B$. sporothermodurans, although detection was possible using the method presented here. An accurate quantification of B. sporothermodurans is important for dairy factories to obtain efficient sterilization and stable UHT products.

\section{ACKNOWLEDGMENTS}

Special appreciation is extended to the laboratory team for assistance to accomplish this work.

\section{REFERENCES}

Ahmed, M. N., D. E. Conner, and D. L. Huffman. 1995. Heat resistance of Escherichia coli O157:H7 in meat and poultry as affected by product composition. J. Food Sci. 60:606-610.

Amador Espejo, G. G., M. M. Hernández-Herrero, B. Juan, and A. J. Trujillo. 2014. Inactivation of Bacillus spores inoculated in milk by ultra high pressure homogenization. Food Microbiol. 44:204-210.

Aouadhi, C., S. Mejri, and A. Maaroufi. 2015. Inhibitory effects of nisin and potassium sorbate alone or in combination on vegetative cells growth and spore germination of $B$. sporothermodurans in milk. Food Microbiol. 46:40-45.

Cattani, F., C. A. Ferreira, and S. D. Oliveira. 2013. The detection of viable vegetative cells of Bacillus sporothermodurans using propidium monoazide with semi-nested PCR. Food Microbiol. 34:196201.

Claeys, W. L., L. R. Ludikhuyze, and M. E. Hendrickx. 2001. Formation kinetics of hydroxymethylfurfural, lactulose and furosine in milk heated under isothermal and non-isothermal conditions. J. Dairy Res. 68:287-301.

El-Sharoud, W. M. 2015. Developing a time and effort-effective, highly sensitive TaqMan probe-based real-time polymerase chain reac- tion protocol for the detection of Salmonella in milk, yoghurt, and cheese. Int. Dairy J. 40:62-66.

European Council. 1992. Directive 92/46. Council of the European Communities of 16 July. Health rules for the production and the trade of raw milk, heat-treated milk, and products based on milk. Off. J. Eur. Community L 268:1-32.

Fernández-No, I. C., M. Guarddon, K. Böhme, A. Cepeda, P. CaloMata, and J. Barros-Velázquez. 2011. Detection and quantification of spoilage and pathogenic Bacillus cereus, Bacillus subtilis and Bacillus licheniformis by real-time PCR. Food Microbiol. 28:605-610.

Gopal, N., C. Hill, P. R. Ross, T. P. Beresford, M. A. Fenelon, and P. D. Cotter. 2015. The prevalence and control of Bacillus and related spore-forming bacteria in the dairy industry. Front. Microbiol. 6:1418. http://dx.doi.org/10.3389/fmicb.2015.01418.

Guarddon, M., J. M. Miranda, J. A. Rodríguez, B. I. Vázquez, A. Cepeda, and C. M. Franco. 2011. Real-time polymerase chain reaction for the quantitative detection of tetA and tetB bacterial tetracycline resistance genes in food. Int. J. Food Microbiol. 146:284-289.

Hammer, P., F. Lembke, G. Suhren, and W. Heeschen. 1995. Characterization of a heat resistant mesophic Bacillus species affecting quality of UHT-milk-A preliminary report. Kieler Milchwirtschaft Forschungsberichte 47:303-311.

Herman, L., M. Heyndrickx, M. Vaerewijck, and N. Klijn. 2000. Bacillus sporothermodurans - A Bacillus forming highly heat-resistant spores. 3. Isolation and methods of detection. Bull. Int. Dairy Fed. 357:9-14.

Herman, L., M. Heyndrickx, and G. Waes. 1998. Typing of Bacillus sporothermodurans and other Bacillus species isolated from milk by repetitive element sequence based PCR. Lett. Appl. Microbiol. $26: 183-188$

Higuchi, R., C. Fockler, G. Dollinger, and R. Watson. 1993. Kinetic PCR analysis - Real-time monitoring of DNA amplification reactions. Biol. Technol. 11:1026-1030.

Klein, D. 2002. Quantification using real-time PCR technology: Applications and limitations. Trends Mol. Med. 8:257-260.

Klijn, N., L. Herman, L. Langeveld, M. Vaerewijck, A. Wagendorp, I. Huemer, and A. Weerkamp. 1997. Genotypical and phenotypical characterization of Bacillus sporothermodurans strains, surviving UHT sterilization. Int. Dairy J. 7:421-428.

Ladero, V., N. Martinez, M. Martin, M. Fernandez, and M. Alvarez. 2010. qPCR for quantitative detection of tyramine-producing bacteria in dairy products. Food Res. Int. 43:289-295.

Larkin, M., G. Blackshields, N. Brown, R. Chenna, P. A. McGettigan, H. McWilliam, F. Valentin, I. M. Wallace, A. Wilm, R. Lopez, J. D. Thompson, T. J. Gibson, and D. G. Higgins. 2007. Clustal W and Clustal X version 2.0. Bioinformatics 23:2947-2948.

Lurchachaiwong, W., S. Payungporn, U. Srisatidnarakul, C. Mungkundar, A. Theamboonlers, and Y. Poovorawan. 2008. Rapid detection and strain identification of porcine reproductive and respiratory syndrome virus (PRRSV) by real-time RT-PCR. Lett. Appl. Microbiol. 46:55-60.

Martínez-Blanch, J. F., G. Sanchez, E. Garay, and R. Aznar. 2009 Development of a real time PCR assay for detection and quantification of enterotoxigenic members of Bacillus cereus group in food samples. Int. J. Food Microbiol. 135:15-21.

McCabe, K. M., Y. H. Zhang, B. L. Huang, E. A. Wagar, and E. R McCabe. 1999. Bacterial species identification after DNA amplification with a universal primer pair. Mol. Genet. Metab. 66:205211.

Montanari, G., A. Borsari, C. Chiavari, G. Ferri, C. Zambonelli, and L. Grazia. 2004. Morphological and phenotypical characterisation of Bacillus sporothermodurans. J. Appl. Microbiol. 97:802-809.

Paul, M., G. M. Baranzoni, S. Albonetti, and J. D. Brewster. 2015 Direct, quantitative detection of Listeria monocytogenes in fresh raw whole milk by qPCR. Int. Dairy J. 41:46-49.

Pettersson, B., F. Lembke, P. Hammer, E. Stackebrand, and G. Fergus, 1996. Bacillus sporothermodurans a new species producing highly heat resistant endospores. Int. J. Syst. Bacteriol. 46:759-764. 
Reichert-Schwillinsky, F., C. Pin, M. Dzieciol, M. Wagner, and I. Hein. 2009. Stress- and growth rate-related differences between plate count and real-time PCR data during growth of Listeria monocytogenes. Appl. Environ. Microbiol. 75:2132-2138.

Scheldeman, P., L. Herman, S. Foster, and M. Heyndrickx. 2006. Bacillus sporothermodurans and other highly heat-resistant spore formers in milk. J. Appl. Microbiol. 101:542-555.

Scheldeman, P., L. Herman, J. Goris, P. De Voe, and M. Hendrickx. 2002. Polymerase chain reaction identification of Bacillus sporothermodurans from dairy source. J. Appl. Microbiol. 92:983-991.

Svec, D., A. Tichopad, V. Novosadova, M. W. Pfaffl, and M. Kubista. 2015. How good is a PCR efficiency estimate: Recommendations for precise and robust qPCR efficiency assessments. Biomol. Detect. Quantif. 3:9-16.

Tabit, F. T., and E. Buys. 2011. Incidence and survival of Bacillus sporothermodurans during processing of UHT milk. Br. Food J. 113:505-518.

Van den Brom, R. V., I. Santman-Berends, S. Luttikholt, L. Moll, E. Van Engelen, and P. Vellema. 2015. Bulk tank milk surveillance as a measure to detect Coxiella burnetii shedding dairy goat herds in the Netherlands between 2009 and 2014. J. Dairy Sci. http:// dx.doi.org/10.3168/jds.2014-9029.

Vaerewijck, M. J., P. De Vos, L. Lebbe, P. Scheldeman, B. Hoste, and M. Heyndrickx. 2001. Occurrence of Bacillus sporothermodurans and other aerobic spore-forming species in feed concentrate for dairy cattle. J. Appl. Microbiol. 91:1074-1084.

West, D. M., K. A. Sprigings, C. Cassar, P. R. Wakeley, J. Sawyer, and R. H. Davies. 2007. Rapid detection of Escherichia coli virulence factor genes using multiplex real-time TaqMan ${ }^{\circledR}$ PCR assays. Vet. Microbiol. 122:323-331.

Zanardi, G., A. Caminiti, G. D. Donne, P. Moroni, A. Santi, G. Galletti, M. Tamba, G. Bolzoni, and L. Bertocchi. 2014. Comparing real-time PCR and bacteriological cultures for Streptococcus agalactiae and Staphylococcus aureus in bulk-tank milk samples. J. Dairy Sci. 97:5592-5598. http://dx.doi.org/10.3168/jds.2014-7947.

Zhang, Z., W. Liu, H. Xu, Z. P. Aguilar, N. P. Shah, and H. Wei. 2015. Propidium monoazide combined with real-time PCR for selective detection of viable Staphylococcus aureus in milk powder and meat products. J. Dairy Sci. http://dx.doi.org/10.3168/jds.2014-8938. 